\title{
A CONGENITAL BRONCHOPULMONARY CYST ASSOCIATED WITH AN ANOMALOUS ARTERY
}

BY

\author{
M. ABUL-WAFA \\ From the Victoria Hospital, Blackpool
}

(RECEIVED FOR PUBLICATION DECEMBER 23, 1953)

Although bronchogenic cysts of the lungs are not very common, the widespread use of mass miniature radiography and check radiography of the chest is revealing more and more of such congenital anomalies. It may therefore be of advantage for radiographers and chest physicians to bear in mind this possibility in the differential diagnosis and appropriate treatment of such cases.

The present case is of interest because there was also a widespread murmur over the chest due to an associated vascular anomaly.

\section{Case History}

A 15-year-old boy who left school before Christmas, 1952, had a routine mass miniature radiograph taken with his schoolmates, and this revealed a shadow lying anteriorly in the right lung (Figs. 1 and 2). He started to work as an apprentice joiner in

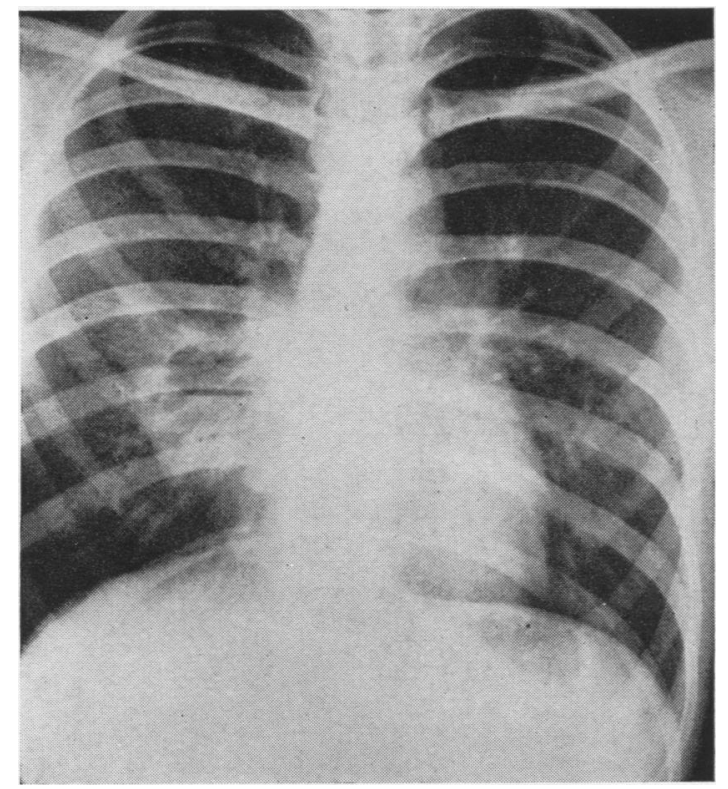

FIG. 1.-Postero-anterior radiograph of the lungs showing a cyst with a fluid level in the right paracardiac area.

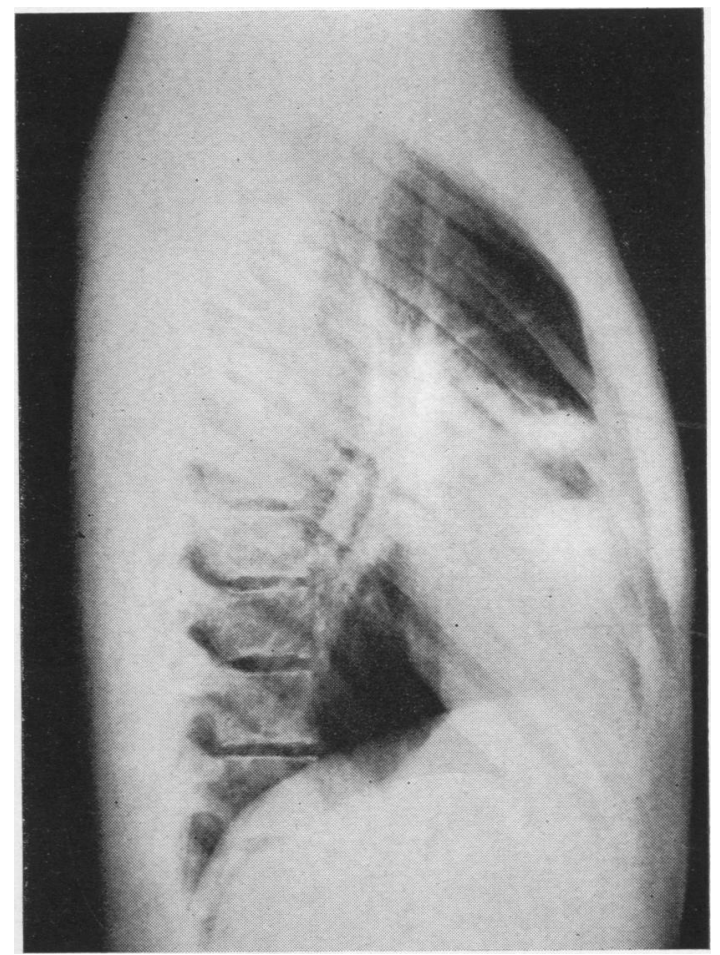

Fig. 2.-Right lateral view showing a cyst with fluid level lying anteriorly in the region of the middle lobe.

1953, but was admitted to hospital for investigation later in the year.

He was asymptomatic, and there was no cough, expectoration, dyspnoea, or loss of weight. He had had measles and chickenpox as a child and tonsillectomy had been performed in 1952. The family history was not available as he is an adopted child, but his father is believed to have died of pulmonary tuberculosis.

On examination he looked a well enough nourished boy of fair intelligence with no cyanosis or finger clubbing. No abnormal signs were discovered in the lungs. The apex beat lay in the fifth space in the midclavicular line; it was forcible and vibrating, but no definite thrill at the apex could be felt (Fig. 3). 
FIG. 3

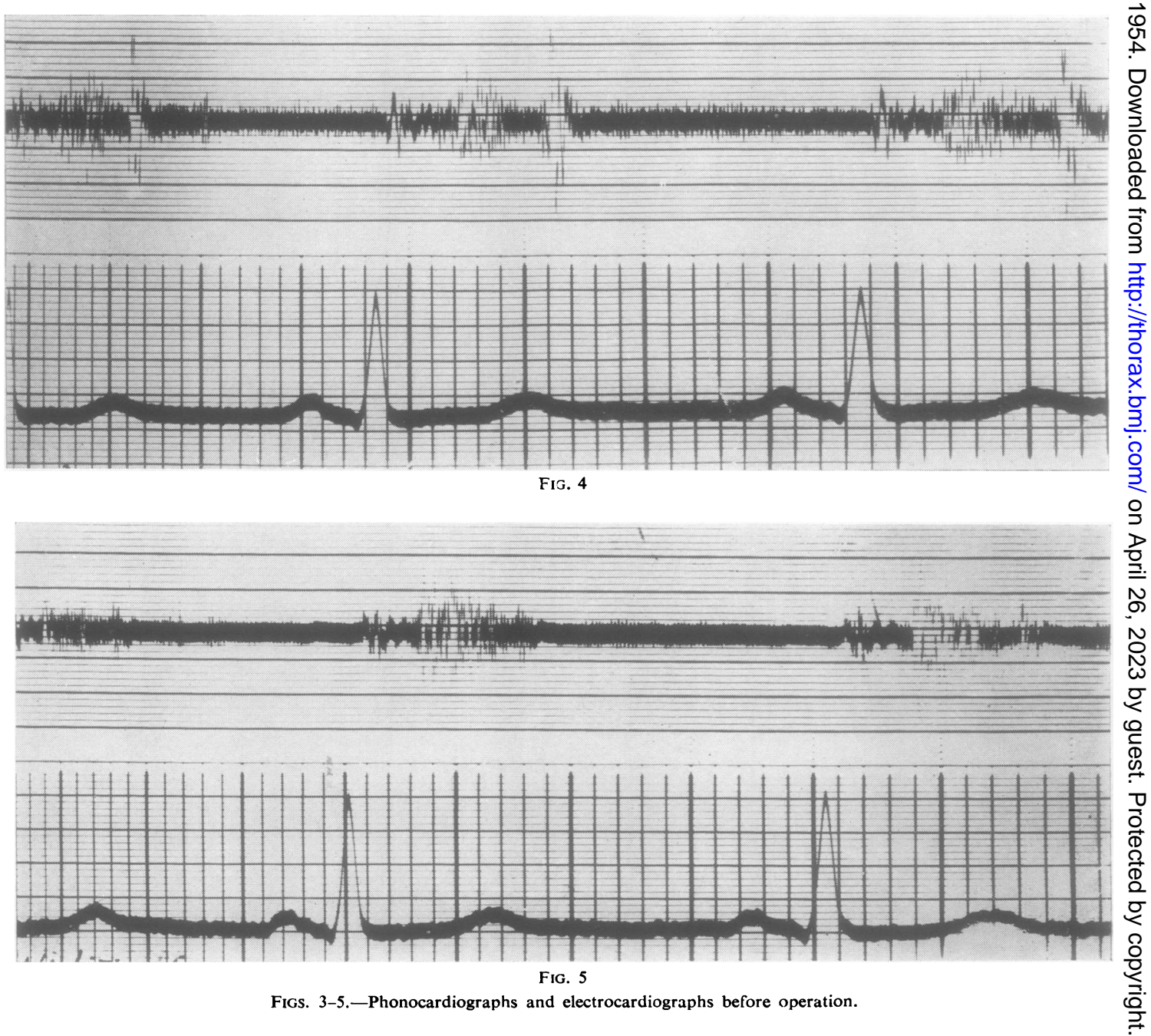




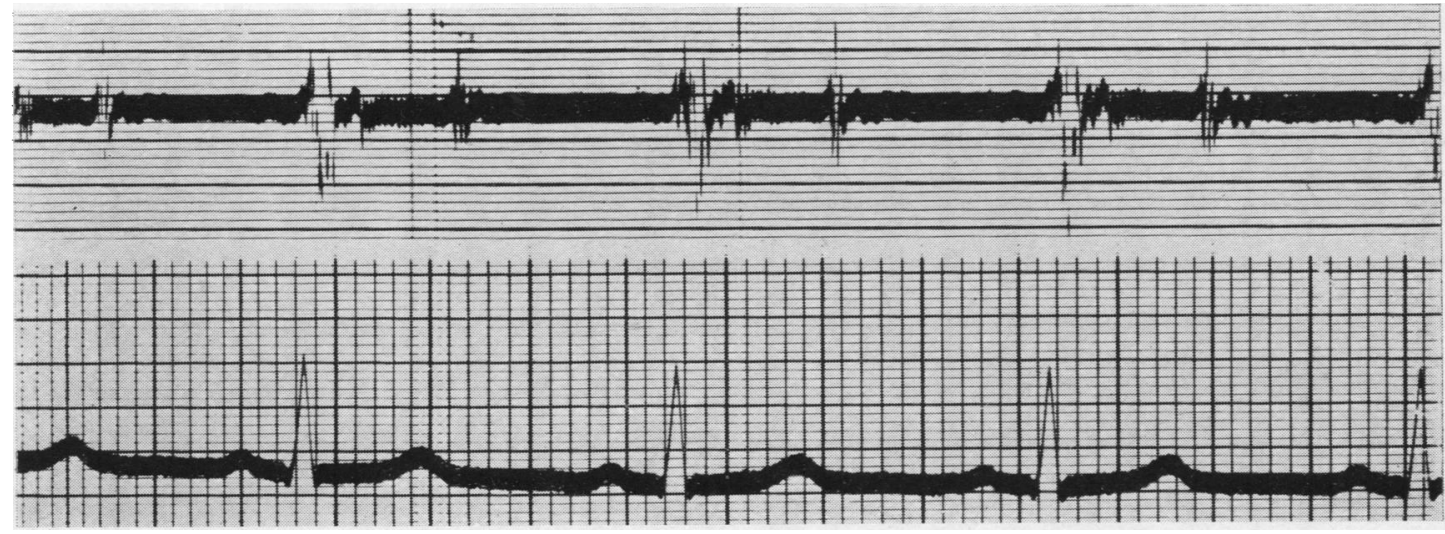
FiG. 6

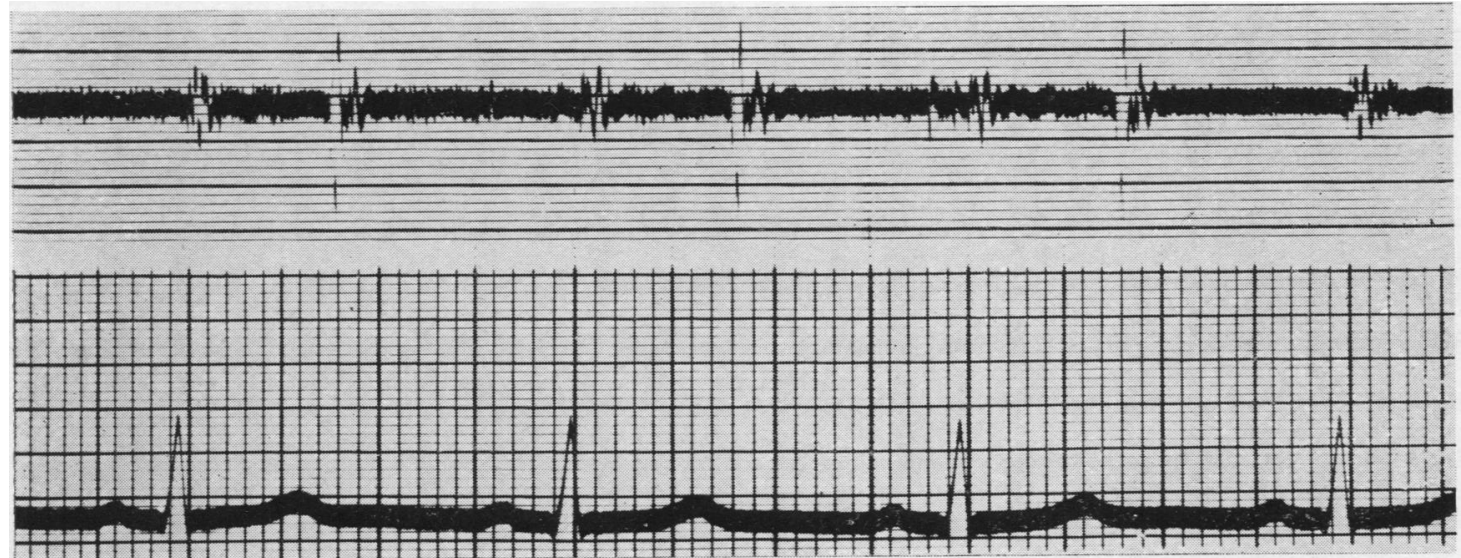
Fig. 7

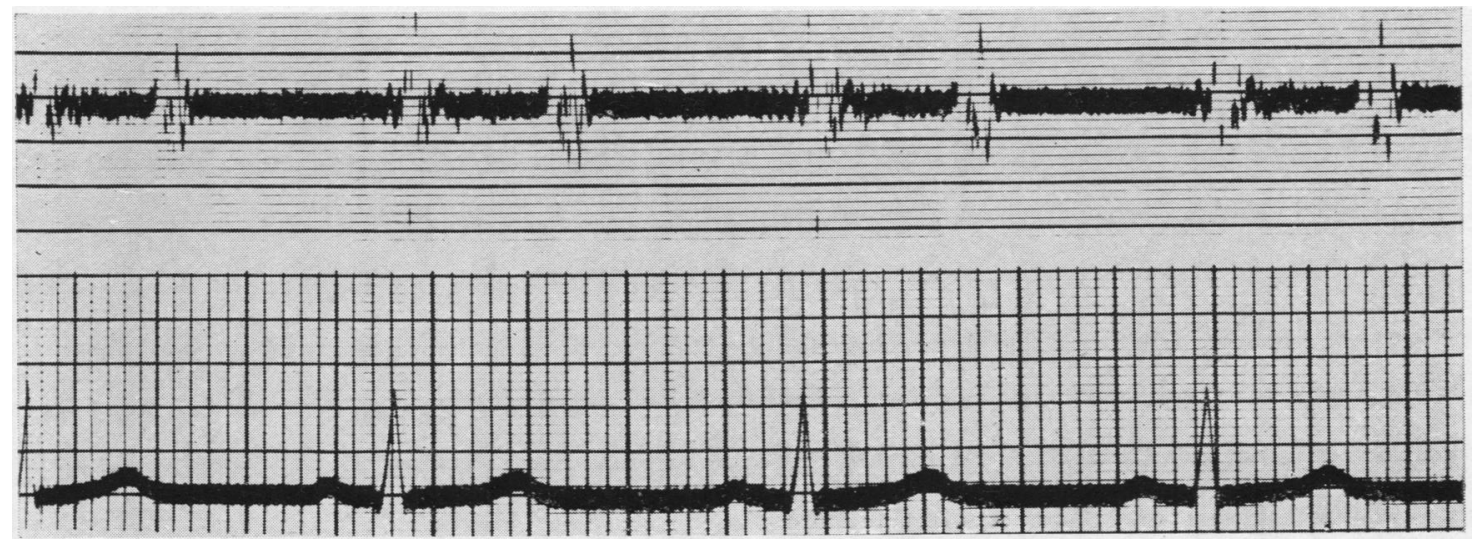

Fig. 8

FiGs. 6-8.-Phonocardiographs and electrocardiographs after operation. 
The outstanding sign was a loud machinery murmur heard over the right upper chest, maximal in the second and third intercostal spaces near the right sternal border (Fig. 4). The murmur was continuous and high pitched with systolic accentuation and was conducted over a wide area anteriorly and to the back. A systolic thrill could also be felt over the right upper sternum. The blood pressure was 130/73 mm. Hg.

In the electrocardiogram T3 was negative, but biphasic radiological examination showed that the pulmonary conus might be slightly enlarged. A phonocardiogram confirmed the presence of a systolic and diastolic murmur in the second and fourth right interspace (Fig. 5).

The patient was given 1.8 million units of distaquaine penicillin daily for two and a half weeks without alteration in the radiological picture. During that period his evening temperature rose to $99^{\circ} \mathrm{F}$. on two occasions but was otherwise normal. The highest white count recorded was 11,000 cells with 5,750 neutrophils. A bronchoscopy was performed, but revealed nothing abnormal. A diagnosis of a pulmonary abscess or infected pulmonary cyst in the right middle lobe was made, and it was thought that this was involving the pulmonary arterial circulation in some way to cause the machinery murmur.

Mr. J. S. Glennie operated on April 15, 1953. The pleura was approached through the bed of the resected fourth rib. It was noted that the vessels of the chest wall bled very fiercely. The pleura was densely adherent to the chest wall over the anterior surface of the middle lobe, and a network of arteries was found in the region of the cyst, which was thought to lie in the middle lobe.

The internal mammary artery was three times its normal size. On palpation a thrill was felt over the anterior surface of the upper lobe. A right middle lobectomy was carried out in the course of which it was found that the cyst was attached to the anterior aspect of the upper lobe, and that there was a very large artery going into the cyst. When the interna? mammary artery was tied the thrill over the upper lobe ceased abruptly. This shortly returned, however, and was not finally abolished until the arter: connecting the upper lobe and cyst was ligatured. After closing the chest no vascular murmur was audible and the thrill could no longer be felt. A considerable quantity of blood was lost during the operation and convalescence was stormy ; but the patient made an excellent recovery. An electrocardiogram now suggests increased right ventricular strain. Post-operative tracings are shown in Figs. 6 to 8 .

The specimen consists of the rignt middle lobe and the cyst, which contained necrotic debris, culture of which was sterile. It was found that the cyst was only attached to the middle lobe by thin fibrous tissue, but it was continuous with the anterior segment of the upper lobe by means of a small bronchus and a large artery (Figs. 9 and 10).

Histological examination of different parts of the cyst wall shows a uniform picture of disorderly bronchial epithelium surrounded by a connective tissue capsule rich in vesseis. There is no evidence of recent infection in the cyst (Figs. 11, 12, and 13).

It is evident that the rich vascular ramification in the wall of the cyst was contributed to by (1) a branch of the anomalous artery, (2) by branches of intercostal arteries, and (3) by tributaries of intercostal veins. No normal pulmonary vesse's took part in its vascular supply, and the venous return and drainage was via the intercostal veins.

The remaining and major part of the systemic anomalous artery continued upwards and pierced the upper lobe, where a systemic pulmonary shunt was established, and this accounted for the machinery murmur and the thrill.

The resumption of the thrill over the upper lobe even after ligature of the internal mammary artery can be explained by the presence of rich vascular collateral channels in the wall of the cyst.

It was observed by Pryce (1946) that the distribution of the anomalous artery could either be to normal lung with no evidence of other pulmonary abnormality, or to the cystic mass plus adjacent normally connected lung (as in the case under discussion) or be confined to the cystic mass.

As to the nature of bronchial attachment to the upper lobe, the absence of any history of respiratory infection, the bacteriological sterility of the cyst contents together with the histological appearance of its wall indicate that the attachment of the vestigial bronchus was primary as distinct from secondary bronchial communication which might have resulted from cyst infection. Infection is known to occur in congenital cysts, even without demonstrable communication with a bronchus by means of direct spread or by haematogenous origin. This implies that the bronchopulmonary mass in this case was sequestrated from the right upper lobe.

The association of pulmonary sequestration with an anomalous pulmonary blood supply has recently been reported by several observers including Pryce (1946), Pryce, Sellors, and Blair (1947), Bruwer, Clagett, and McDonald (1950), and Kergin (1952).

The usual clinical picture is a recurrent productive cough with or without haemoptysis; there may be bouts of fever or a state consistent with recurrent pneumonia. The presumptive diagnosis was commonly of pneumonia, bronchiectasis, or basal empyema, or was an accidental finding as in cases reported by Wyman and Eyler (1952).

Radiologically there is some abnormality at the base of one or other lower lobes, more commonly the left, which may show as an opacity or cyst with a fluid level. 


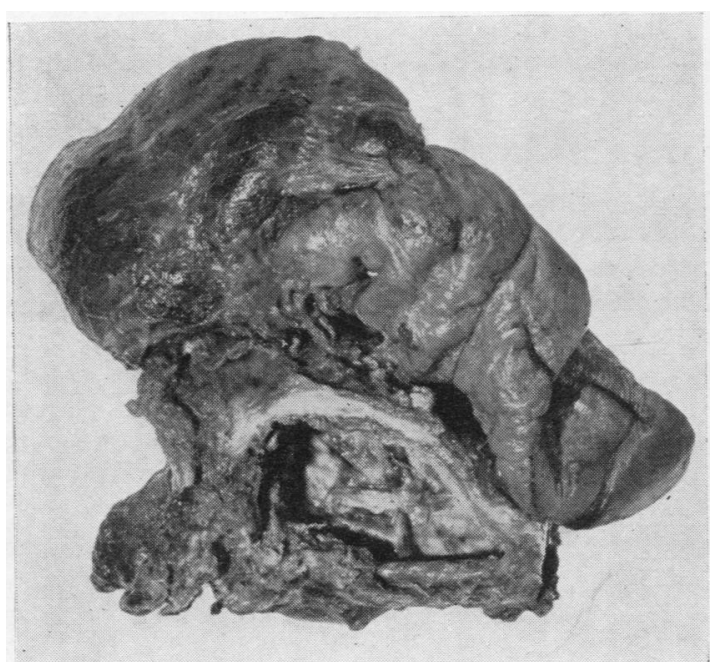

Fig. 9

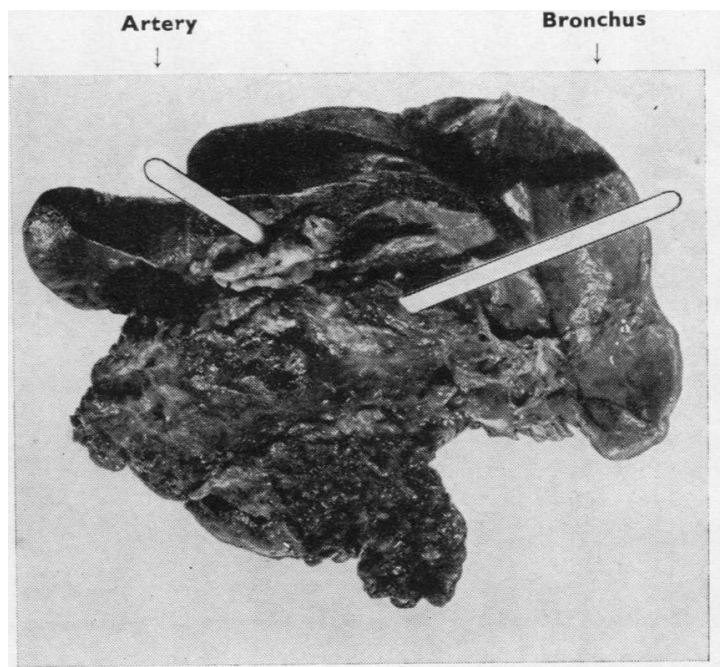

Fig. 10

Figs. 9 and 10.-The operation specimen. In Fig. 10 the middle lobe is seen behind the mass.

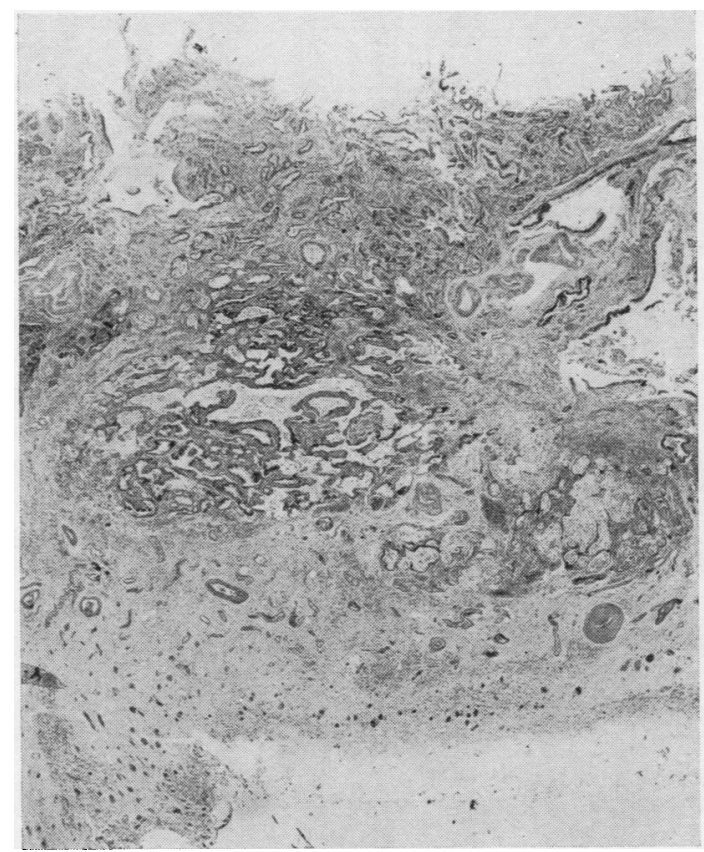

FIG. 11

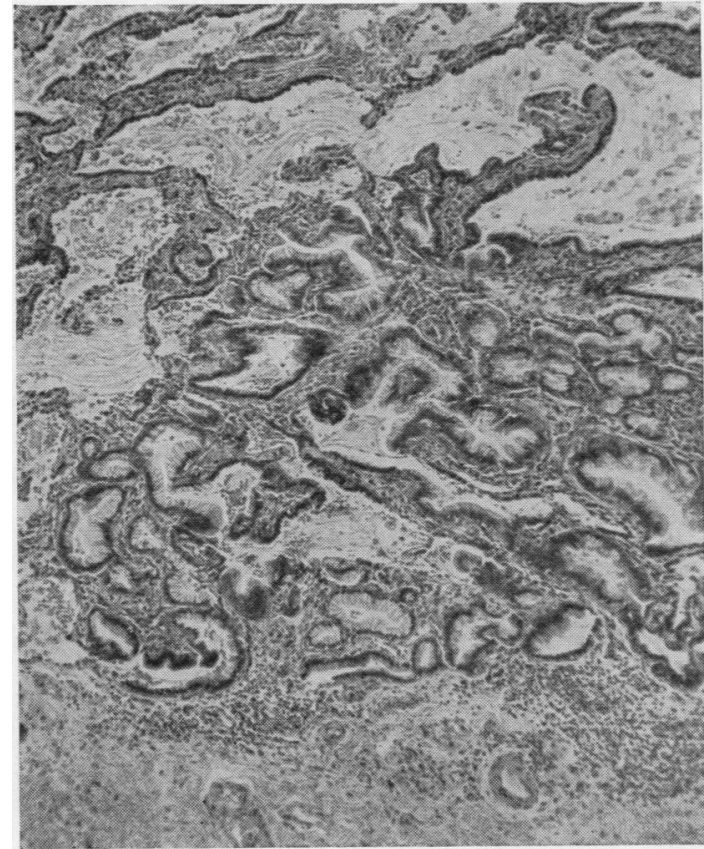

Fig. 12

Figs. 11 and 12.-Photomicrographs of the cyst wall. $\times 15$ and $\times 70$.

On thoracotomy a systemic artery emerging from the aorta above or below the diaphragm is found to pass in the pulmonary ligament and to supply a sequestrated segment of the lower lobe, usually the posterior basal lobe. The latter shows a fairly constant pathological picture, namely, it consists of a mass of unaerated primitive lung tissue devoid of pigment and containing one or more bronchial cysts. A connexion with the bronchial system of the normal lobe may or may not be demonstrable, even when the cyst is found to be aerated. No vein accompanies the anomalous 


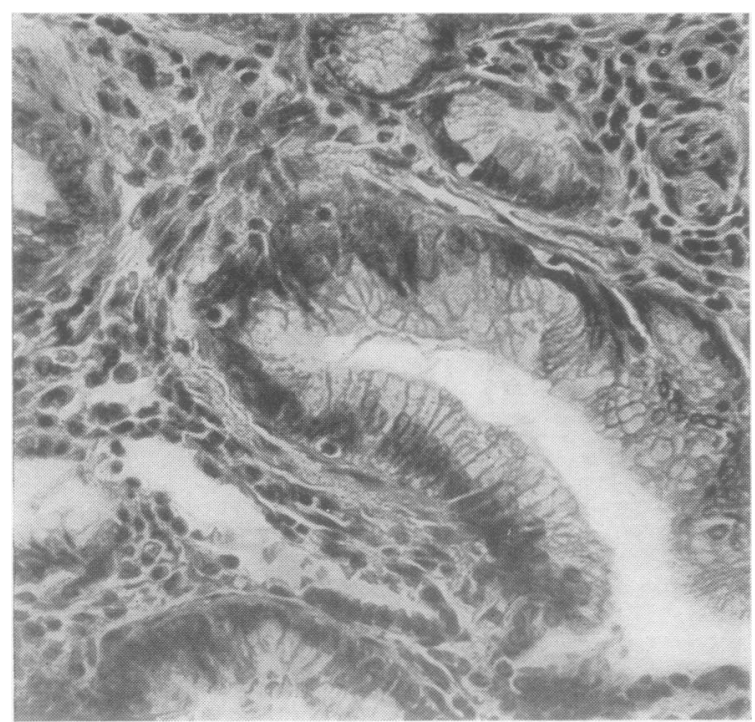

FIG. 13.-Photomicrograph of cyst wall. $\times 320$

artery except in some cases of extralobar sequestration, and the veins then terminate directly or indirectly into the hemi-azygous veins.

It is suggested by Kergin (1952) that there is evidence of direct and considerable anastomosis between the systemic anomalous arterial supply and the tributaries of the pulmonary vein, which leads, if of sufficient degree, to burdening the left ventricle by a useless shunt analogous to an arteriovenous aneurysm (case 5 in his series).

The blood carried by the anomalous artery, whether to the norm 1 or to the sequestrated lung, is already oxygenated and passes unaltered to the venous side. Further, the sequestrated mass is incapable of any function.

Pulmonary arterial ramifications may or may not be demonstrable in the primitive tissue.

In the case cited above, although such a shunt was not anatomically demonstrated, the characteristic loud continuous murmur can only be explained by an abundant communication between the high pressure systemic vessel and the low pressure circulation, namely, the pulmonary vein tributaries in the upper lobe. This fact is an argument in favour of Kergin's view.
The accepted conception for the aetiology of $\stackrel{\overrightarrow{\vec{s}}}{+}$ such combined anomalies is that introduced by Pryce (1946) and Pryce and others (1947). He $\frac{0}{\omega}$ states that the vascular anomaly is the primary condition, and that in the course of development $\triangle$ of the lung the bulbous tip of one branch of the primitive bronchus is appropriated by one of the $\overrightarrow{0}$ growing embryonic vessels, and therefore remains cut off to a greater or less extent from the rest of $\vec{\omega}$ the lobe.

\section{SUMMARY AND COMMENT}

A condition, radiologically consistent with pul- $\vec{\sigma}$ monary abscess, was accidentally revealed on mass miniature radiography in a boy of 15 who was symptomless.

Clinically the only sign was a loud continuous systolic-diastolic murmur heard maximally over $\overparen{\curvearrowright}$ the right second and third intercostal spaces near $\vec{e}$ the sternum accompanied by a systolic thrill.

Subsequent thoracotomy has shown the abnormality to be a congenital bronchopulmonary mass with an anomalous systemic arterial supply and to be situated in front of the right middle lobe.

A brief review of some other combined con- $\frac{2}{D}$ genital anomalies in the lung is cited.

The case differs from most of the series described because (1) it was revealed before infection took place, (2) the lobe was sequestrated from the right upper lobe, (3) its anomalous systemic supply came from the internal mammary artery, and (4) it showed a peculiar machinery murmur to the right of the sternum, due to a systemic pulmonary shunt $\frac{\times}{\sigma}$ in the substance of the right upper lobe.

I wish to express my thanks to Dr. W. J. Hay, of the Royal Infirmary, Lancaster, and to Mr. J. S. Glennie, of Victoria Hospital, Blackpool, for their kind permission to publish this case, and I am indebted to Dr. Hay for providing the specimen, photomicrographs, and E.C.G. tracings.

\section{REFERENCES}

Bruwer, A., Clagett, O. T., and McDonald, J. R. (1950). J. thorac. Surg., 19, 957

Kergin, F. G. (1952). Ibid., 23, 55

Pryce, D. M. (1946). J. Path. Bact., 58, 457.

Pryce, Sellors, T. H., and Blair, L. G. (1947). Brit. J. Surg., 35, 18. Wyman, S. M., and Eyler, W. R. (1952). Radiology, 59, 658 . 